\title{
Adsorption of methyl tert-butyl ether using granular activated carbon: Equilibrium and kinetic analysis
}

\author{
${ }^{1}$ D. Z. Chen; ${ }^{2}$ J. X. Zhang; ${ }^{1} *$ J. M. Chen \\ ${ }^{1}$ College of Biological and Environmental Engineering, Zhejiang University of Technology, Hangzhou 310032, China \\ ${ }^{2}$ Yuhuan County Environmental Protection Bureau, Yuhuan 317600, China
}

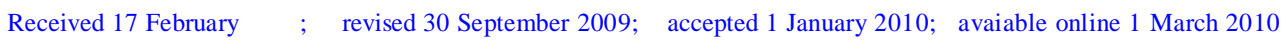

\begin{abstract}
The adsorption of methyl tert-butyl ether by granular activated carbon was investigated. The experimental data were analyzed using the Freundlich isotherm and the Langmuir isotherm. Although equilibrium data were found to follow Freundlich isotherm model, it were fitted better by the Langmuir model with a maximum adsorption capacity of $204.1 \mathrm{mg} / \mathrm{g}$. The kinetic data obtained at different concentrations were analyzed to predict the constant rate of adsorption using three common kinetic models: pseudo-first-order, pseudo-second-order equation and intraparticle diffusion equation. The pseudo-second-order model was suitable for describing the adsorption kinetics for the removal of methyl tert-butyl ether from aqueous solution onto granular activated carbon. Both the Lagergren first-order rate constant $k_{1}$ and pseudo-second-order rate constant $k_{2}$ decrease with increasing initial concentrations of methyl tert-butyl ether and the intraparticle diffusion rate constant $k_{p}$ shows the reverse characteristic. Analysis of sorption data using a boyd plot confirmed that external mass transfer is the main rate-limiting step at the initial stage of adsorption. Results illustrate that granular activated carbon is an effective adsorbent for methyl tert-butyl ether and also provide specific guidance into adsorption of methyl tert-butyl ether on granular activated carbon in contaminated groundwater.
\end{abstract}

Keywords: Adsorption equilibrium; Intraparticle diffusion model; Mechanism; Modeling

\section{INTRODUCTION}

Methyl tert-butyl ether (MTBE) is a kind of fuel additive used as a replacement for lead to promote combustion efficiency and to reduce air pollution (Squillace et al., 1996). However, with the widespread use of MTBE, it has become one of the most frequently detected underground water pollutants caused by gasoline leaking from underground storage tanks, pipelines and other components of gasoline distribution systems (Kharoune et al., 2001). MTBE has been classified as a possible human carcinogen by the U.S. Environmental Protection Agency (Johnson et al., 2000). Moreover, MTBE is reported to induce a variety type of deoxyribonucleic acid (DNA) damage such as single-strand breaks, doublestrand breaks and oxidative base modification (Chen et al., 2008). Now, water resources are severely threatened by MTBE due to its low odor and taste threshold of about 2 2.5 $\mu \mathrm{g} / \mathrm{L}$ (Fiorenza and Rifai, 2003). To date, MTBE-related problems have spread

*Corresponding Author Email: jchen@zjut.edu.cn

Tel.: +86571 8832 0386; Fax: +86571 88320882 worldwide including USA, Europe and Asia (Squillace et al., 1996; Achten and Puttmann, 2000; Hsieh et al., 2006; Ayotte et al., 2008). Therefore, there has been a growing concern regarding the treatment of MTBEcontaminated groundwater in recent years (Suidan $e t$ al., 2005; Chen et al., 2008, 2009). Given its high aqueous solubility, MTBE removal by traditional treatment technologies, such as air stripping has been expected to be less effective (Chang and Young, 2000; Soltanali and Shams Haghani, 2008). The byproducts of advanced oxidation process have prevented this technique from general application though it is quite effective in removing MTBE (Acero et al., 2001). Granular activated carbon (GAC) adsorption is a widely used technology for treating water contaminated with many taste- and odor-causing organics and synthetic organic chemicals, either independently or coupled with biological degradation (Suffet and Wable, 1995; El Diwani et al., 2009). Some researches have reported that GAC could successfully remove MTBE from contaminated water (Wilhelm et al., 2002; Shih et al., 
2003; Sutherland et al., 2004) mainly due to its welldeveloped porous internal structure and large surface area (Yang and Al-Duri, 2005). The systemic investigation on the kinetic and mechanism of MTBE adsorption has not reported. In order to optimize the design and operation of an adsorption system for wastewater treatment, it is essential to study the adsorption equilibrium and kinetics which could supply the fundamental information of adsorption (AbdelGhani et al., 2009). Although various models were used to describe the adsorption kinetics, most of them need many parameters which require lots of experiments and massive calculation time. Therefore, several simplified models using lumped parameter were developed, which could also explain the whole adsorption process for many adsorption systems. Two widely used models are the Lagergren first-order kinetic model and pseudosecond-order model which assume the driving force of adsorption is the difference between the equilibrium concentration $q_{e}$ and the adsorbate uptake $q$ (Chang et al., 2003; Chang and Juang, 2004; Ozcan et al., 2004). Another well-known lumped kinetic model is the intraparticle diffusion model which assumes that the film diffusion is negligible and intraparticle diffusion is the only rate controlling step (Wu et al., 2001; Chang and Juang, 2004).

The objective of this research is to study the adsorption mechanism of MTBE from aqueous solution onto GAC and to further evaluate the validity of common isotherm models and kinetic models. The research was carried out in the laboratory (Hangzhou, China) during the period of March to December in 2008.

\section{MATERIALS AND METHODS}

MTBE with purity greater than $99.8 \%$, supplied by Tedia Company (USA), was employed as adsorbate. The adsorbent used in this study is GAC (Shanghai Activated Carbon Corporation, China) which was washed thoroughly in distilled water to remove the suspension residues and dried at $105^{\circ} \mathrm{C}$ for at least 24 h. Its physical properties were as follows: particle size, 18-30 mesh fraction; particle density, $0.69 \mathrm{~g} / \mathrm{cm}^{3}$; true density, $1.17 \mathrm{~g} / \mathrm{cm}^{3}$; particle porosity computed from particle density and true density, 0.41 .

To determine the adsorption isotherms, MTBE of different initial concentrations was added to the sealed serum bottles with $200 \mathrm{~mL}$ aqueous solutions containing fixed concentration of GAC $(1 \mathrm{~g} / \mathrm{L})$. Then the bottles were shaken in a rotary shaker $(28.0 \pm 0.5$
${ }^{\circ} \mathrm{C}, 160 \mathrm{r} / \mathrm{min}$ ) for eight days to attain equilibrium. Each experiment was carried out in triplicate. The effect of the initial MTBE concentrations on adsorption kinetics was investigated. The adsorption was carried out in $250 \mathrm{~mL}$ sealed serum bottles with the same concentration of GAC $(1 \mathrm{~g} / \mathrm{L})$ and MTBE at initial concentrations of $57.2,126.3,180,235.4 \mathrm{mg} / \mathrm{L}$, respectively. The solution was stirred by a rotary shaker $\left(28.0 \pm 0.5^{\circ} \mathrm{C}, 160 \mathrm{r} / \mathrm{min}\right)$ and samples from three parallel replicates were taken at predetermined time intervals. The concentration of MTBE in liquid phase was determined by a gas chromatography (Agilent 6890N, USA) equipped with a silica HP-Innowax capillary column (30 m × $0.32 \mathrm{~mm} \times 0.5 \mu \mathrm{m}$, J \& W Scientific, USA) and a flame ionization detector. The operating conditions were as follows: injector, $250^{\circ} \mathrm{C}$; oven, 80 ${ }^{\circ} \mathrm{C}$ for $4 \mathrm{~min}$ and then programmed to $160^{\circ} \mathrm{C}$ at the rate of $30^{\circ} \mathrm{C} / \mathrm{min}$ and detector, $300^{\circ} \mathrm{C}$. The amount of MTBE adsorbed was determined as:

$$
q=\left(C_{0}-C_{t}\right) V / W
$$

\section{RESULTS AND DISCUSSION}

Adsorption isotherm in water solution

Adsorption isotherm study provides fundamental physiochemical data for evaluating the adsorption capacities of an adsorbent, one of the most important criteria in selecting a suitable adsorbent. In the present investigation, the isotherm data were analyzed using the Langmuir and Freundlich isotherm equations (Figs. 1 and 2). The Langmuir sorption isotherm (Kim et al., 2004) is the best and the Freundlich isotherm (Chang et al., 2003) is an empirical equation most frequently used to describe the adsorption of inorganic and organic components in solution, respectively expressed as:

Langmuir: $q_{e}=\frac{q_{m} K_{L} C_{e}}{1+K_{L} C_{e}}$

Freundlich: $q_{e}=K_{f} \times C_{e}^{1 / n}$

The linearized form of above equations can be written as follows:

$$
\begin{aligned}
& \frac{1}{q_{e}}=\frac{1}{q_{m} K_{L} C_{e}}+\frac{1}{q_{m}} \\
& \ln q_{e}=\ln K_{f}+\frac{1}{n} \ln C_{e}
\end{aligned}
$$




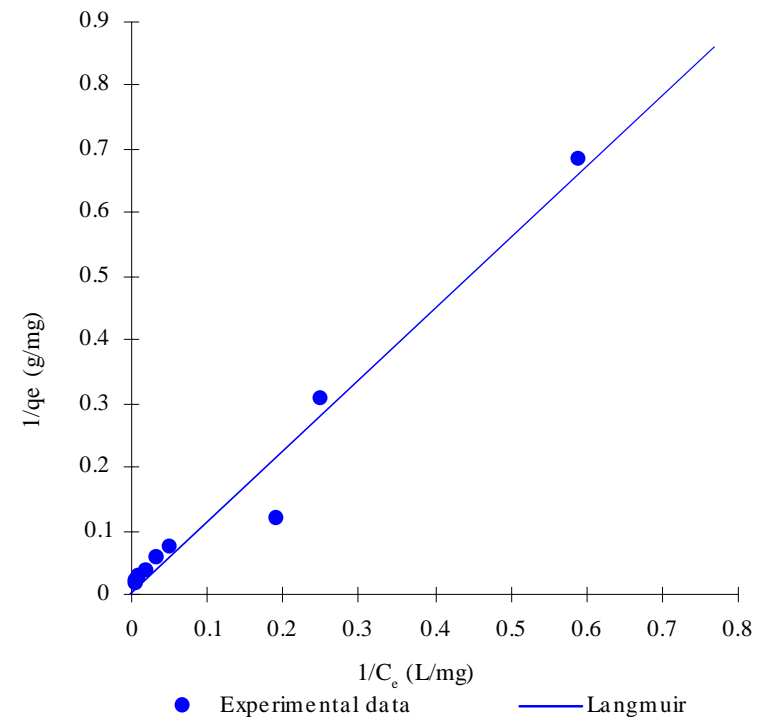

Fig. 1: Experimental data and predicted Langmuir isotherm of MTBE in water solution onto GAC. (Sorbent dose: $1 \mathrm{~g} /$ $\mathrm{L}$; shaker speed: $160 \mathrm{r} / \mathrm{min}$; temp.: $28.0 \pm 0.5^{\circ} \mathrm{C}$; contact time: 8 days)

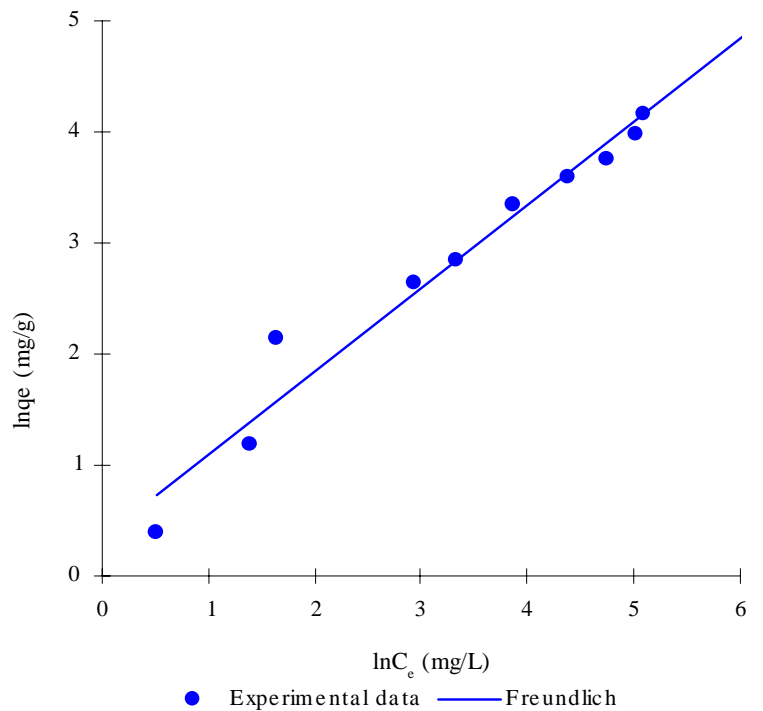

Fig. 2: Experimental data and predicted Freundlich isotherm of MTBE in water solution onto GAC. (Sorbent dose:1 $\mathrm{g} / \mathrm{L}$; shaker speed:160 r/min; temp.: $28.0 \pm 0.5^{\circ} \mathrm{C}$; contact time: 8 days)

Table 1: Parameter values from fitting the adsorption equilibrium data with isotherm models

\begin{tabular}{lcccc}
\hline & Langmuir & \multicolumn{3}{c}{ Freundlich } \\
\hline$q_{m}(\mathrm{mg} / \mathrm{g})$ & $K_{L}(\mathrm{~L} / \mathrm{mg})$ & $R^{2}$ & $K_{f}(\mathrm{mg} / \mathrm{g})(\mathrm{L} / \mathrm{mg})^{1 / \mathrm{n}}$ & $n$ \\
204.1 & 4.39 & 0.9722 & 1.39 & $R^{2}$ \\
\hline
\end{tabular}

If the adsorption follows the Langmuir equation, a plot of $1 / q_{e}$ versus $1 / C_{e}$ should be a straight line. $q_{m}$ and $K_{L}$ can be determined from the intercept and slope. Similarly, from a plot of $\ln q_{e}$ against $\ln C_{e}, K_{f}$ and $n$ can be computed. Table 1 shows the results of the Langmuir and Freundlich isotherm, indicating the reasonably good correlation between the experiment and both the two models, as reflected by correlation coefficients $\left(R^{2}\right)$ in the value of 0.972 and 0.963 . The fact that the Langmuir isotherm fits the experimental data well may be due to the homogenous distribution of active sites on GAC. The maximum sorption capacity $q_{m}$ of GAC for MTBE attained from the intercept is $204.1 \mathrm{mg} / \mathrm{g}$, reflecting that GAC has good capacity adsorbing MTBE. Moreover, the value of $n$ was computed as 1.33 between 1 and 10, which also display the good sorption capacity of GAC for MTBE (Ben Hamissa et al., 2008). Ji et al. (2009) claimed that MTBE adsorption on the nonpolar porous polymer and chloromethylated polymer followed Langmuir adsorption model, which is somewhat in accord with the phenomenon of present work. The adsorption capacity of GAC for MTBE adsorption may be dependent on both pore structure and surface chemistry of the adsorbents (Ji et al., 2009).

\section{Adsorption kinetics}

The effect of MTBE at different initial concentrations on the adsorption kinetics is shown in Fig. 3. It reveals that the adsorbate uptake $q$ increases with increasing initial concentrations. In the diagram, the slope at each point of the curve denotes the transient adsorption rate $(d q / d t)$. Fig. 3 shows that at all initial MTBE concentrations, the adsorption rate decreases with the contact time until it gradually approaches a plateau because the driving force $\left(q_{e}-q\right)$ continuously decreases with time.

In the present study, the instantaneous adsorption of the batch process at different initial concentrations of MTBE was investigated using the Lagergren first-order kinetic model and pseudo- 


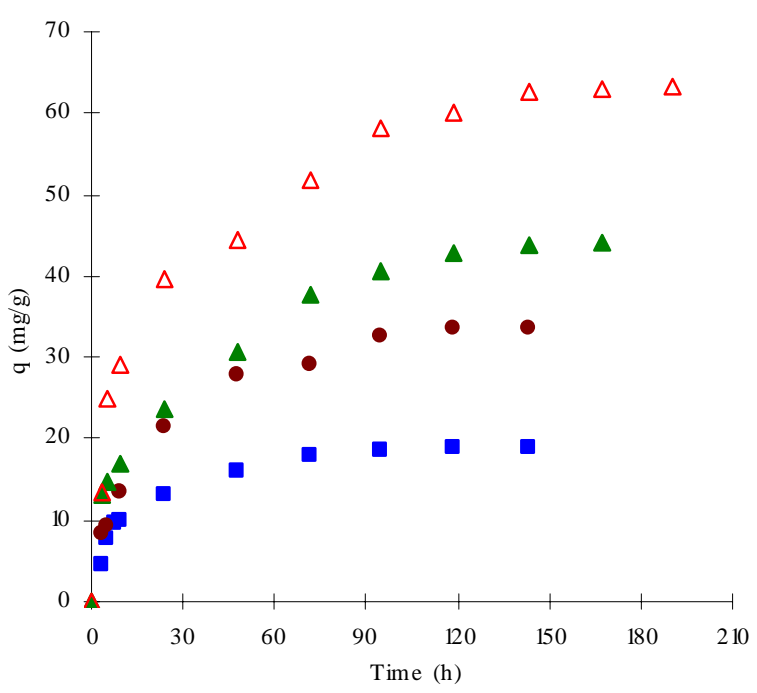

— $57.2 \mathrm{mg} / \mathrm{L} \bullet 126.3 \mathrm{mg} / \mathrm{L} \Delta 180 \mathrm{mg} / \mathrm{L} \quad \Delta 235.4 \mathrm{mg} / \mathrm{L}$

Fig. 3: The adsorption of MTBE at different initial concentrations onto GAC. (Agitation speed: $160 \mathrm{r} / \mathrm{min}$; sorbent dose: $1 \mathrm{~g} / \mathrm{L}$; temperature: $28.0 \pm 0.5{ }^{\circ} \mathrm{C}$.)

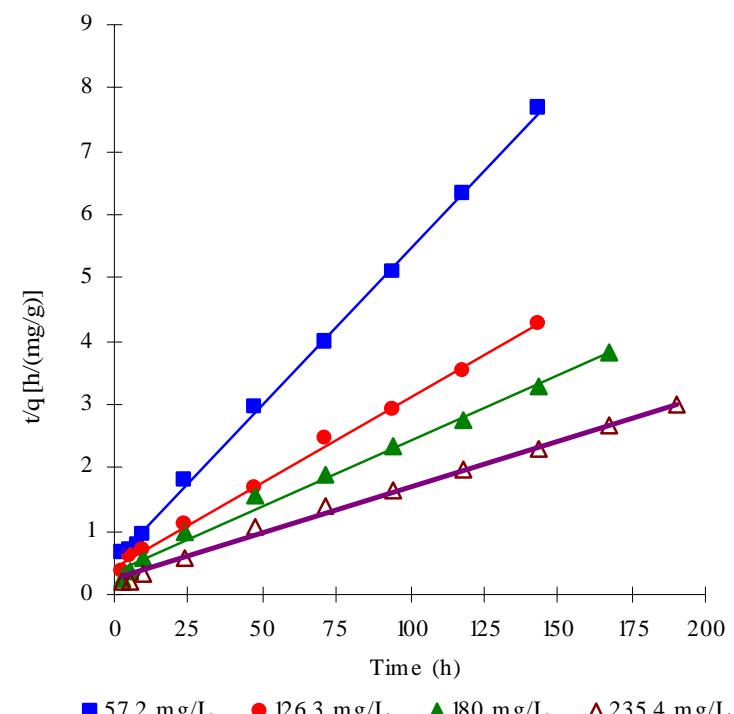

Fig. 5: Pseudo-second-order plot for MTBE sorption onto GAC

second-order model (Yang and Al-Duri, 2005), respectively represented as:

$\frac{d q}{d t}=k_{1}\left(q_{e}-q\right)$
$\frac{d q}{d t}=k_{2}\left(q_{e}-q\right)^{2}$

(7) $\frac{t}{q}=\frac{1}{k_{2} q_{e}{ }^{2}}+\frac{t}{q_{e}}$

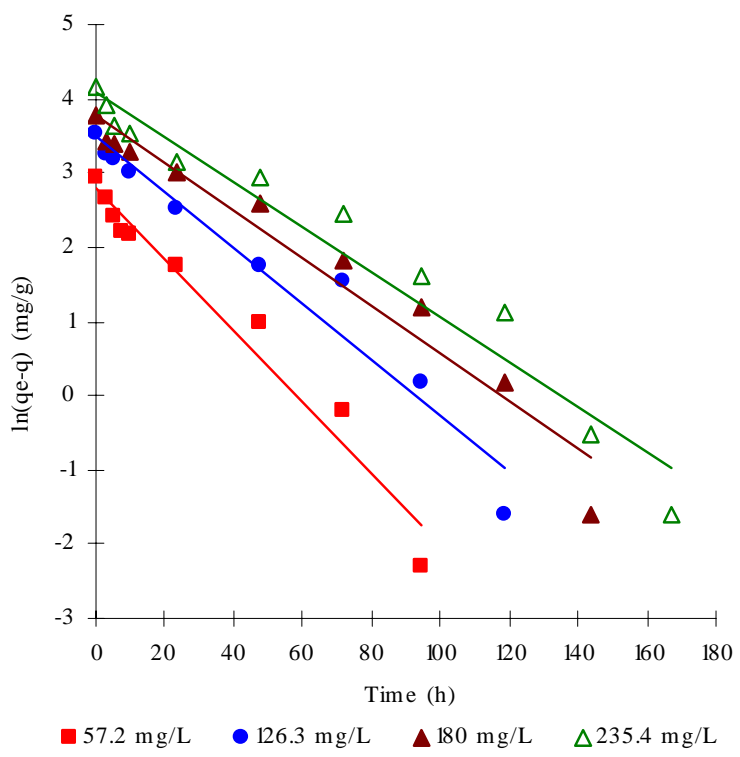

Fig. 4: Lagergren plot for MTBE sorption onto GAC

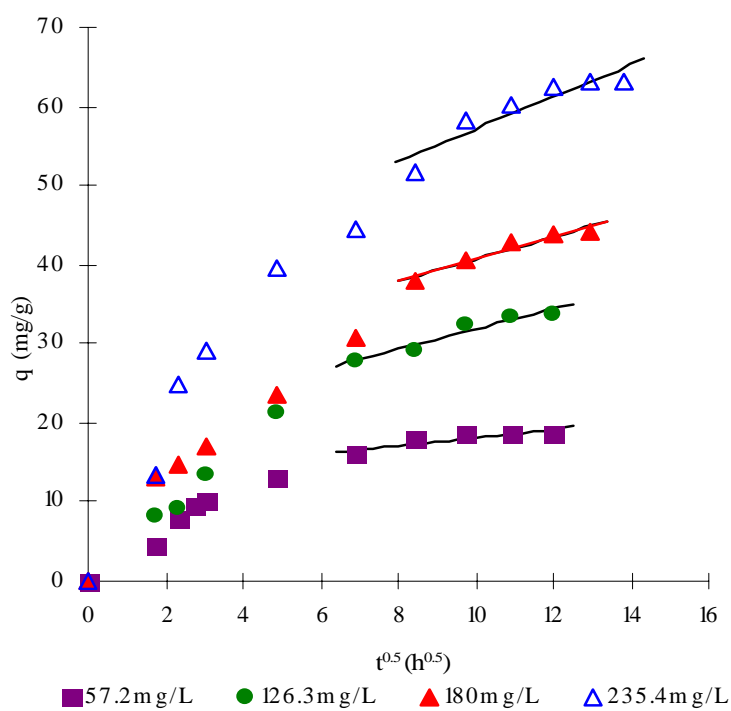

Fig. 6: Inraparticle diffusion plot for MTBE sorption onto GAC

Integrating the above equations for the boundary conditions $t=0$ to $t=t$ and $q=0$ to $q=q$ gives 
Constant $k_{1}$ and $q_{e}$ can be calculated from the plot of $\ln \left(q_{e}-q\right)$ versus time ( $\left.t\right)$. Similarly, the plot of $t / q$ against $t$ gives the value of $k_{2}$ and $q_{e}$.

Figs. 4 and 5 show that at all initial MTBE concentrations, the experimental data are both well represented by the Lagergren model and the pseudosecond-order model. The values of rate parameters and correlation coefficient $R^{2}$ have been obtained and listed in Table 2. It is observed that the pseudosecond-order model yields a somewhat better fit than the Lagergren model by comparing the results of correlation coefficients. It could be concluded that the mechanism of adsorption was pseudo-secondorder reaction. This conclusion is consistent with those studies demonstrating that the pseudosecond-order kinetic model is reasonably good fit of data over the entire adsorption process (Wu et al., 2001; Chang et al., 2003; Chang and Juang, 2004;

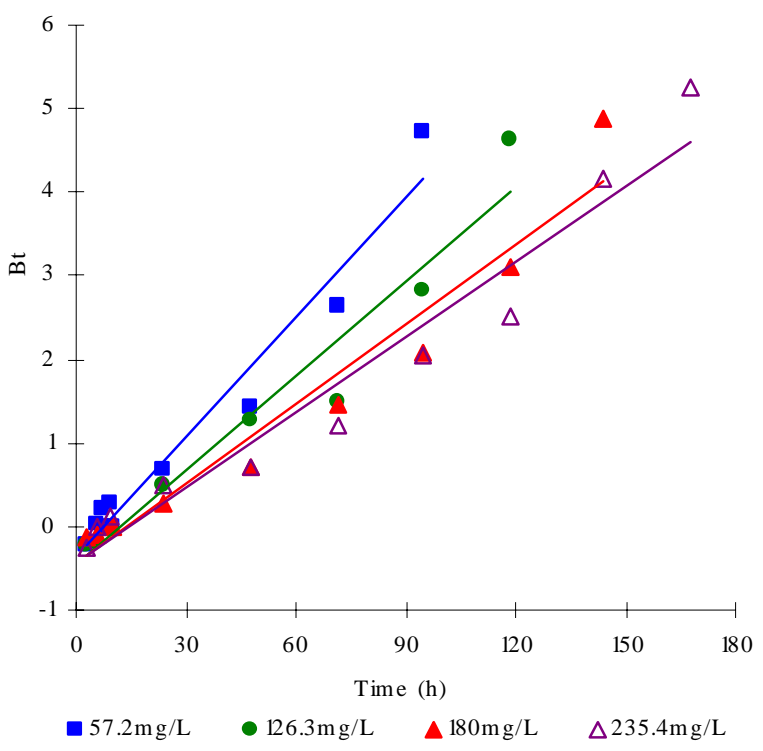

Fig. 7: Boyd plot for MTBE adsorption onto GAC
Ozcan et al., 2004). Clearly, it is seen that when the initial MTBE concentration increases, the equilibrium concentration $q_{e}$ increases accordingly. Furthermore, Table 2 illustrates that both the rate constants $k_{1}$ and $k_{2}$ decrease with increasing initial MTBE concentrations, which reveals the fact that it is faster for an adsorption system with MTBE at lower initial concentrations to reach equilibrium. This trend is compatible with those observed for other adsorption systems (Wu et al., 2001; Chang et al., 2003; Rengaraj et al., 2004). Because the above two equations could not definitely reveal the adsorption mechanism, another kinetic model named intraparticle diffusion model was used in the present study (Yang et al., 2005). The formation of this model is as follows:

$q=k_{p} t^{0.5}$

$k_{p}=\frac{6 q_{e}}{R} \sqrt{\frac{D}{\pi}}$

If the adsorption process follows the inraparticle diffusion model, a plot of $q$ against $t^{0.5}$ should be a straight line. $k_{p}$ can be calculated from the slope of the straight line. Nevertheless, it is common to observe multilinearity on the $q-t^{0.5}$ plot, which reveals the different stages in adsorption involving external mass transfer and intraparticle diffusion (Yang et al., 2005).

The intraparticle diffusion plot for the adsorption of MTBE onto GAC is shown in Fig. 6. It is observed that there are two linear portions which elucidate the two adsorption stages: external mass transfer at initial period, then followed by intraparticle diffusion of MTBE onto GAC. The slope of the second linear portion suggests the rate of intraparticle diffusion listed in Table 2 which shows that $k_{p}$ increases with increasing initial MTBE concentration. From Eq.11,

Table 2: Kinetic parameters for MTBE sorption onto GAC

\begin{tabular}{rcccccccc}
\hline \multirow{2}{*}{$C_{0}(\mathrm{mg} / \mathrm{L})$} & \multirow{2}{*}{$\begin{array}{c}\text { Experimental } \\
q_{e}(\mathrm{mg} / \mathrm{g})\end{array}$} & \multicolumn{3}{c}{ Lagergren first-order } & \multicolumn{2}{c}{ Pseudo-second-order } & \multicolumn{2}{c}{$\begin{array}{c}\text { Intraparticle } \\
\text { diffusion }\end{array}$} \\
\cline { 3 - 8 } & & $q_{e}(\mathrm{mg} / \mathrm{g})$ & $k_{1}\left(\mathrm{~h}^{-1}\right)$ & $R^{2}$ & $q_{e}(\mathrm{mg} / \mathrm{g})$ & $k_{2}(\mathrm{~g} / \mathrm{mg} / \mathrm{h})$ & $R^{2}$ & $k_{p}\left(\mathrm{mg} / \mathrm{g} / \mathrm{h}^{0.5}\right)$ \\
\hline 57.2 & 18.7 & 16.5 & 0.0482 & 0.9621 & 20.16 & 0.00497 & 0.9989 & 0.51285 \\
126.3 & 33.7 & 32.8 & 0.0377 & 0.9545 & 37.4 & 0.00168 & 0.9973 & 1.27812 \\
180 & 44 & 43.61 & 0.0322 & 0.9550 & 48.36 & 0.00118 & 0.9916 & 1.40141 \\
235.4 & 63.2 & 60.19 & 0.0302 & 0.9564 & 68.12 & 0.00094 & 0.9955 & 2.02965 \\
\hline
\end{tabular}


it can be seen that $k_{p}$ is proportional to both $q_{e}$ and $D^{1 / 2}$. The equilibrium concentration $q_{e}$ increases accordingly with the increasing initial MTBE concentration. Moreover, some studies have reported that the intraparticle diffusion, $D$, increases with the increasing initial concentration (AlDuri and Mckay, 1991; Chatzopoulos et al., 1993; Yang et al., 2003). Consequently, the constant $k_{p}$ increases with increasing initial concentration due to the increasing $q_{e}$ and $D^{1 / 2}$. In order to interpret the rate-controlling step during the adsorption process, the experimental data are further analyzed by the model given by Boyd (Boyd et al., 1947).

$$
F=1-\frac{6}{\pi^{2}} \exp (-B t)
$$

Since $F$ is equal to $q / q_{e}$, Bt could be represented as follows:

$$
B t=-0.4977-\ln \left(1-\frac{q}{q_{e}}\right)
$$

The value of $B t$ against time $(t)$ is plotted in Fig. 7 employed to characterize the particle diffusion control mechanism (Kumar et al., 2005). It is shown that the plots are linear but do not pass through the origin, signifying that external mass transfer is the main rate controlling step at the initial stages. A similar observation was previously reported by Kumar et al. (2005). When the amounts of organic molecules which have reached external activated carbon increase to a certain degree, the sorption process becomes intraparticle-diffusion-controlled.

\section{CONCLUSION}

The adsorption equilibrium and kinetics of MTBE onto GAC have been studied in the present work. The equilibrium data could be fitted by both the Langmuir isotherm model and the Freundlich isotherm model which reflect that GAC has good capacity adsorbing MTBE. The adsorption kinetic data have been respectively analyzed by the Lagergren first-order model, the pseudo-secondorder model and the intraparticle diffusion model. The results indicate that the adsorption of MTBE onto GAC could be best described by the pseudosecond-order model. Both the rate constants $k_{1}$ and $k_{2}$ decrease with increasing initial concentrations of MTBE and $k_{\mathrm{p}}$ shows the reverse characteristic due to the increasing $q_{e}$ and $D^{1 / 2}$. Analysis of mechanism reveals that the adsorption process of MTBE onto GAC includes two stages: external mass transfer at initial period, then followed by intraparticle diffusion. At the initial stage of adsorption, external mass transfer is the main rate controlling step. When the amounts of organic molecule which have reached external activated carbon increase to a certain degree, the sorption process becomes intraparticlediffusion-controlled.

\section{ACKNOWLEDGMENTS}

This study was sponsored by National Natural Science Foundation of China (Grant No. 20907043). In addition, authors also would like to thank Chen Xiao and Cheng Zhuowei for their assistance in conducting the whole experiment.

\section{Nomenclature}

$C_{0}$ the initial concentration of the MTBE solution (mg/L)

$C_{t}$ the liquid phase concentration of the MTBE solution at time $t(\mathrm{mg} / \mathrm{L})$

$C_{e}$ the equilibrium liquid-phase concentration of $\operatorname{MTBE}(\mathrm{mg} / \mathrm{L})$

$V$ the volume of the MTBE solution (mL)

$W$ the mass of the dry adsorbent (g)

$q$ the amount of MTBE adsorbed onto the solid phase at any time $(\mathrm{mg} / \mathrm{g})$

$q_{e}$ the amount of adsorption to GAC at equilibrium (mg/g)

$q_{m}$ a constant related to the monolayer coverage of adsorbate onto the adsorbent which reflects the adsorption capacity (mg/g)

$t$ time (h)

$K_{L}$ Langmuir isotherm constant (L/mg)

$K_{f}$ Freundlich isotherm constant [(mg/g) $\left.(\mathrm{L} / \mathrm{mg})^{1 / \mathrm{n}}\right]$

$n$ Freundlich exponent related to adsorption intensity.

$k_{1}$ the Lagergren first-order adsorption rate constant $\left(\mathrm{h}^{-1}\right)$

$k_{2}$ the pseudo-second-order adsorption rate constant (g/mg/h)

$k_{p}$ the intraparticle diffusion rate constant $\left(\mathrm{mg} / \mathrm{g} / \mathrm{h}^{0.5}\right)$

$R$ the particle radius $(\mathrm{cm})$

$D$ the intraparticle diffusivity constant

$F$ the fractional uptake at time $t$

$B$ a mathematical function of $F$

$R^{2}$ squared regression correlation coefficient 


\section{REFERENCES}

Abdel-Ghani, N. T.; Hegazy, A. K.; El-Chaghaby, G. A., (2009). Typha domingensis leaf powder for decontamination of aluminium, iron, zinc and lead: Biosorption kinetics and equilibrium modeling. Int. J. Environ. Sci. Tech., 6 (2), 243248 (6 pages).

Acero, J. L.; Haderlein, S. B.; Schmidt, T. C.; Suter, M. J. F.; Von Gunten, U., (2001). MTBE oxidation by conventional ozonation and the combination ozone/hydrogen peroxide: efficiency of the processes and bromate formation. Environ. Sci. Tech. 35 (21), $4252-4259$ (8 pages).

Achten, C.; Puttmann, W., (2000). Determination of methyl tert-butyl ether in surface water by use of solid-phase microextraction. Environ. Sci. Tech., 34, 1359-1364 (6 pages).

AlDuri, B.; McKay, G., (1991). Prediction of binary-system for kinetics of batch adsorption using basic-dyes onto activated carbon. Chem. Eng. Sci., 46 (1), 193-204 (12 pages).

Ayotte, J. D.; Argue, D. M.; McGarry, F. J.; Degnan, J. R.; Hayes, L.; Flanagan, S. M.; Helsel, D. R., (2008). Methyl tert-butyl ether (MTBE) in public and private wells in New Hampshire: Occurrence, factors and possible implications. Environ. Sci. Tech., 42, 677-684 (8 pages).

Ben Hamissa, A. M.; Ncibi M. C.; Mahjoub, B.; Seffen, M., (2008). Biosorption of metal dye from aqueous solution onto Agave americana (L.) fibres. Int. J. Environ. Sci. Tech., 5 (4), 501-508 (8 pages).

Boyd, G. E.; Adamson, A. W.; Meyers, L. S., (1947). The exchange adsorption of ions from aqueous solutions by organic zeolites II. J. Am. Chem. Soc., 69, 2836-2848 (13 pages).

Chang, C. Y.; Tsai, W. T.; Ing, C. H.; Chang, C. F., (2003). Adsorption of polyethylene glycol (PEG) from aqueous solution onto hydrophobic zeolite. J. Coll. Interf. Sci., 260 (2), 273-279 (7 pages).

Chang, M. Y.; Juang, R. S., (2004). Adsorption of tannic acid, humic acid, and dyes from water using the composite of chitosan and activated clay. J. Colloid Interf. Sci., 278 (1), 18-25 (8 pages).

Chang, P. B. L.; Young, T. M., (2000). Kinetics of methyl tert-butyl ether degradation and by-product formation during UV/hydrogen peroxide water treatment. Water Res., 34 (8), 2233-2240 (8 pages).

Chatzopoulos, D.; Varma, A.; Irvine, R. L., (1993). Activated carbon adsorption and desorption of toluent in the aqueousphase. Aiche. J., 39 (12), 2027-2041 (15 pages).

Chen, C. S.; Hseu, Y. C.; Liang, S. H.; Kuo, J. Y.; Chen, S. C., (2008). Assessment of genotoxicity of methyl-tert-butyl ether, benzene, toluene, ethylbenzene and xylene to human lymphocytes using comet assay. J. Hazard. Mater., 153, 351-356 (6 pages).

Chen, D. Z.; Chen, J. M.; Zhong, W. H., (2009). Enhancement of methyl tert-butyl ether degradation by the addition of readily metabolizable organic substrates. J. Hazard. Mater., 167 (1-3), 860-865 (6 pages).

Chen, D. Z.; Chen, J. M.; Zhong, W. H.; Cheng, Z. W., (2008). Degradation of methyl tert-butyl ether by gel immobilized Methylibium petroleiphilum PM1. Bioresour. Tech., 99 (11), 4702-4708 (7 pages).
El Diwani, G.; El Rafie, S.; Hawash, S., (2009). Degradation of 2, 4, 6-trinitotoluene in aqueous solution by ozonation and multi-stage ozonation biological treatment. Int. J. Environ. Sci. Tech., 6 (4), 619-628 (10 pages).

Fiorenza, S.; Rifai, H. S., (2003). Review of MTBE biodegradation and bioremediation. Bioremed. J., 7 (1), 135 (35 pages).

Hsieh, L. T.; Yang, H. H.; Chen, H. W., (2006). Ambient BTEX and MTBE in the neighborhoods of different industrial parks in Southern Taiwan. J. Hazard. Mater., 128 (2-3), 106-15 (10 pages).

Ji, B.; Shao, F.; Hu, G.; Zheng, S.; Zhang, Q.; Xu, Z., (2009). Adsorption of methyl tert-butyl ether (MTBE) from aqueous solution by porous polymeric adsorbents. J. Hazard. Mater., 161 (1), 81-87 (7 pages).

Johnson, R.; Pankow, J.; Bender, D.; Price, C.; Zogorski, J., (2000). MTBE - To what extent will past releases contaminate community water supply wells? Environ. Sci. Tech., 34, 210A-217A (8 pages).

Kharoune, M.; Pauss, A.; Lebeault, J. M., (2001). Aerobic biodegradation of an oxygenatesmixture: ETBE, MTBE and TAME in an upflow fixed-bed reactor., Water Res., 35 (7), 1665-1674 (10 pages).

Kim, Y. H.; Kim, C. M.; Choi, I. H.; Rengaraj, S.; Yi, J. H., (2004). Arsenic removal using mesoporous alumina prepared via a templating method. Environ. Sci. Tech., 38 (3), 924-931 (8 pages).

Kumar, K. V.; Ramamurthi, V.; Sivanesan, S., (2005). Modeling the mechanism involved during the sorption of methylene blue onto fly ash. J. Colloid Interf. Sci., 284 (1), 14-21 (8 pages).

Ozcan, A. S.; Erdem, B.; Ozcan, A., (2004). Adsorption of Acid Blue 193 from aqueous solutions onto Na-bentonite and DTMA-bentonite. J. Coll. Interface Sci., 280 (1), 4454 (11 pages).

Rengaraj, S.; Kim, Y.; Joo, C. K.; Yi, J., (2004). Removal of copper from aqueous solution by aminated and protonated mesoporous aluminas: kinetics and equilibrium. J. Coll. Interf. Sci., 273 (1), 14-21 (8 pages).

Shih, T. C.; Wangpaichitr, M.; Suffet, M., (2003). Evaluation of granular activated carbon technology for the removal of methyl tertiary butyl ether (MTBE) from drinking water. Water Res., 37 (2), 375-385 (11 pages).

Soltanali, S.; Shams Hagani, Z., (2008). Modeling of air stripping from volatile organic compounds in biological treatment processes. Int. J. Environ. Sci. Tech., 5 (3), 353360 (8 pages).

Squillace, P. J.; Zogorski, J. S.; Wilber, W. G.; Price, C. V., (1996). Preliminary assessment of the occurrence and possible sources of MTBE in groundwater in the United States, 1993-1994. Environ. Sci. Tech., 30 (5), 1721 1730 (10 pages).

Suffet, I. H.; Wable, O., (1995). Removal of taste-and-odor compounds by activated carbon, in: Suffet, I. H.; Mallevialle, J.; Kawczyski, E. (Eds.), Advances in tasteand-odor treatment and control. American Water Works Research Foundation, Colombia.

Suidan, M. T.; Esperanza, M.; Zein, M.; McCauley, P.; Brenner, R. C.; Venosa, A. D., (2005). Challenges in biodegradation of trace organic contaminants - Gasoline oxygenates and 
sex hormones. Water Environ. Res., 77 (1), 4-11 (8 pages).

Sutherland, J.; Adams, C.; Kekobad, J., (2004). Treatment of MTBE by air stripping, carbon adsorption, and advanced oxidation: Technical and economic comparison for five groundwaters. Water Res., 38 (1), 193-205 (13 pages).

Wilhelm, M. J.; Adams, V. D.; Curtis, J. G.; Middlebrooks, E. J., (2002). Carbon adsorption and air-stripping removal of MTBE from river water. J. Environ. Eng., 128 (9), 813-823 (11 pages).
Wu, F. C.; Tseng, R. L.; Juang, R. S., (2001). Kinetic modeling of liquid-phase adsorption of reactive dyes and metal ions on chitosan. Water Res., 35 (3), 613-618 (6 pages).

Yang, X. Y.; Al-Duri, B., (2005). Kinetic modeling of liquidphase adsorption of reactive dyes on activated carbon. J. Coll. Interf. Sci., 287 (1), 25-34 (10 pages).

Yang, X. Y.; Otto, S. R.; Al-Duri, B., (2003). Concentrationdependent surface diffusivity model (CDSDM): Numerical development and application. Chem. Eng. J., 94 (3), 199209 (11 pages).

\section{AUTHOR (S) BIOSKETCHES}

Chen, D. Z., Lecturer, College of Biological and Environmental Engineering, Zhejiang University of Technology, China.

Email: cdz@zjut.edu.cn

Zhang, J. X., Staffer, Yuhuan County Environmental Protection Bureau, China. Email: eaglejiak928@sina.com

Chen, J. M., Full Professor, College of Biological and Environmental Engineering, Zhejiang University of Technology, Chief of Environmental Science and Engineering Research Institute, China. Email: jchen@zjut.edu.cn

How to cite this article: (Harvard style)

Chen, D. Z.; Zhang, J. X.; Chen, J. M., (2010). Adsorption of methyl tert-butyl ether using granular activated carbon: Equilibrium and kinetic analysis. Int. J. Environ. Sci. Tech., 7 (2), 235-242. 